\title{
APLIKASI MOTOR LISTRIK SEBAGAI PEMOTONG KAYU DENGAN PENGATURAN KECEPATAN BERBASIS PWM
}

\author{
Yunianto Wahyu Ismail ${ }^{1}$, Muhamad $\mathrm{Ali}^{2}$ \\ 1,2 Jurusan Pendidikan Teknik Elektro, Fakultas Teknik, Universitas Negeri Yogyakarta \\ email : wahyuismail1995@gmail.com
}

\begin{abstract}
The purpose of this project is to be able to find out the design and the performance of wood cutter with $P W M$ based speed regulator driven by AC motor 1 phase capacitor start type with transmission system using $v$ belt and pulley, covering current, power, voltage, time cutting and costs required. This tool is expected to increase production and quality in souvenirs craft industry and carving craft.The method of making wood cutting device with PWM-based speed regulator driven by AC motor 1 phase capacitor start type with $R \& D$ approach (Research and Development). Stages consisting of 1) Needs analysis, 2) device designing, 3) device making, 4) device testing, 5) implentation. The mechanism of this cutting device will produce a motion force which will then move the driving shaft that works principle such as the piston on the vehicle, then will move the saw up and down by using AC motor 1 phase capacitor start which is equipped with PWM-based speed controller, pulley transmission system and v-belt. Results from wood cutter with PWM-based speed regulator. This tool is able to cut wood with a circle from the thickness of $0.5 \mathrm{~cm} / 88 \mathrm{~s}, 1 \mathrm{~cm} / 135 \mathrm{~s}, 2 \mathrm{~cm} / 180 \mathrm{~s}$, and $3 \mathrm{~cm} /$ $1560 \mathrm{~s}$ with good cut quality and with a diameter of $12 \mathrm{~cm}$ circle. Then the measured power starts from 255.75 watt-333 watts depending on the thickness of the sawed timber.
\end{abstract}

Keywords :Cutting wood device, PWM, AC Motor 1 fase

\begin{abstract}
ABSTRAK
Tujuan penelitian ini adalah untuk dapat mengetahui rancang bangun dan mengetahui unjuk kerja dari pemotong kayu dengan pengatur kecepatan berbasis PWM yang digerakkan oleh motor AC 1 fasa jenis kapasitor start dengan sistem transmisi menggunakan sabuk v-belt dan pulley, meliputi arus, daya, tegangan, waktu pemotongan dan biaya yang dibutuhkan. Alat ini diharapkan dapat meningkatkan produksi dan kualitas pada industri kerajinan souvenir dan kerajinan ukir. Metode pembuatan alat pemotong pemotong kayu dengan pengatur kecepatan berbasis PWM yang digerakkan oleh motor AC 1 fasa jenis kapasitor start dengan pendekatan R\&D (Research and Development). Tahap-tahap yang terdiri dari 1) analisis kebutuhan, 2) perancangan alat, 3) pembuatan alat, 4) pengujian alat, 5) implentasi. Mekanisme alat pemotong ini akan menghasilkan gaya gerak yang kemudian akan menggerakan poros penggerak yang prinsip kerjanya seperti piston pada kendaraan, kemudian akan menggerakkan gergaji naik turun dengan menggunakan motor AC 1 fasa jenis kapasitor start yang dilengkapi dengan pengendali kecepatan berbasis PWM, sistem transmisi pulley dan sabuk v. Hasil dari pemotong kayu dengan pengatur kecepatan berbasis PWM. Alat ini mampu memotong kayu dengan lingkaran dari mulai ketebalan $0.5 \mathrm{~cm} / 88 \mathrm{~s}, 1 \mathrm{~cm} / 135 \mathrm{~s}, 2 \mathrm{~cm} / 180 \mathrm{~s}$, dan $3 \mathrm{~cm} / 1560 \mathrm{~s}$ dengan kualitas potongan yang halus dan baik dengan diameter lingkaran $12 \mathrm{~cm}$. Kemudian daya yang terukur mulai dari 255.75 watt-333 watt tergantung dengan ketebalan kayu yang digergaji.
\end{abstract}

Kata kunci: Alat pemotong kayu, PWM, motor AC 1 fasa

\section{PENDAHULUAN}

Dlingo merupakan salah satu kecamatan yang ada di Kabupaten Bantul, Yogyakarta yang saat ini sedang banyak dikembangkan dengan berbagai tujuan pariwisata. Kekayaan pesona alam yang di miliki Kecamatan Dlingo membuat wisatawan domestik maupun mancanegara tertarik untuk mengunjungi kecamatan ini. Selain terkenal dengan obyek 
wisata alamnya Kecamatan Dlingo juga masih menyimpan kekayaan lainnya, seperti kesenian, makanan khas pedesaan dan kerajinan (meubel) baik dari bambu maupun dari kayu.

Kerajinan merupakan salah satu bidang usaha yang paling maju di Dlingo dan menjadi bidang usaha yang paling banyak menyerap tenaga kerja. Kerajinan ukiran merupakan salah satu kerajinan yang mampu menembus pasar mancanegara. Produksi kerajinan ukiran di Kecamatan Dlingo sendiri sampai saat ini terus berkembang, hingga di Dlingo memiliki SMK yang salah satu jurusannya khusus mempelajari tentang berbagai kerajinan dari kayu.

Secara nyata kerajinan ukiran menjadi salah satu andalan pendapatan masyarakat di kecamatan Dlingo. Hal ini ditandai dengan banyak ditemui industri kerajinan ukiran yang menjamur, salah satunya yang ada di Mangunan, Dlingo, Bantul, Daerah Istimewa Yogyakarta. Ukiran adalah proses pembuatan kerajinan yang umumnya menggunakan bantuan alat gergaji jigsaw atau scroll saw untuk membuat pola dasar, gergaji jigsaw atau scroll saw tersebut biasanya dioperasikan dengan kecepatan yang tidak bisa diatur.

Berbagai jenis kayu yang akan dibuat kerajinan ukiran dibentuk dahulu pola dasarnya menggunakan gergaji jigsaw. Kecepatan jigsaw ini dapat mempengaruhi kualitas pemotongan pada kayu. Misal pemotongan dilakukan pada bagian yang tidak lurus tentunya kecepatan gergaji harus secara perlahan, agar kayu mudah untuk digerakkan atau dibentuk, apabila kecepatannya tinggi menyebabkan kayu akan sulit untuk dibentuk dan kayu dikhawatirkan akan pecah, kayu yang memiliki tekstur tidak terlalu keras, seperti Sengon dan Mahoni, jika di gergaji dengan kecepatan yang konstan, kualitas potongannya tidak bagus dan kehalusannya sangat kurang.

Penelitian ini dimulai dengan pembuatan alat pemotong menggunakan motor AC sebagai penggeraknya, agar kecepatannya dapat diatur tanpa harus memindahkan v-belt maka dibutuhkan menambahkan pengatur kecepatan berbasis PWM sebagai pengatur kecepatannya. Dengan pembuatan alat ini, diharapkan dapat membantu pengrajin ukiran dalam melaksanakan pekerjaannya.

\section{METODE}

Proses pembuatan alat dilaksanakan dengan mengikuti Flowchart yang ditunjukkan dalam gambar 1.

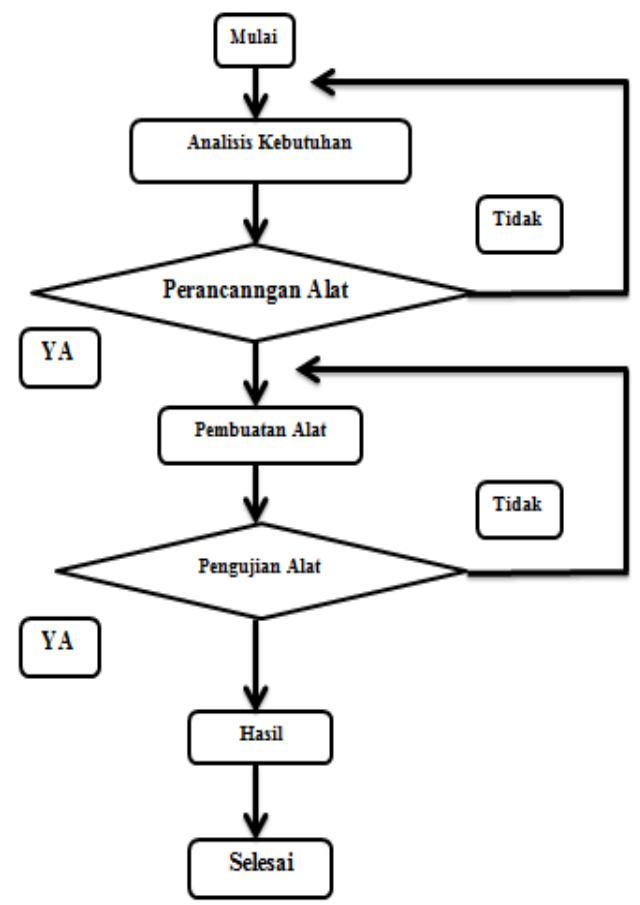

Gambar 1. Flowchart pembuatan alat

Unit kerangka dari alat pemotong kayu dengan pengaturan kecepatan berbasis PWM

Sebelum dilakukan pembuatan rangka mesin dilakukan pemilihan besi siku, besi lempengan untuk penutup, besi lonjongan bulat, besi bentuk persegi panjang dan besi lonjoran berbentuk pipih. 


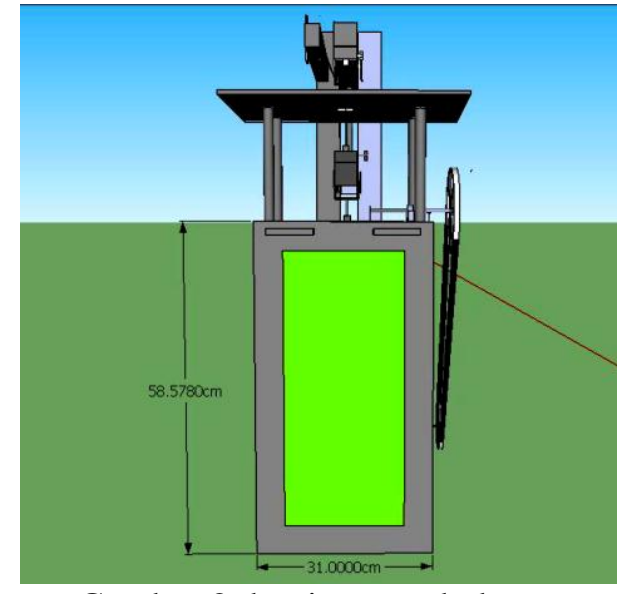

Gambar 2 desain tampak depan

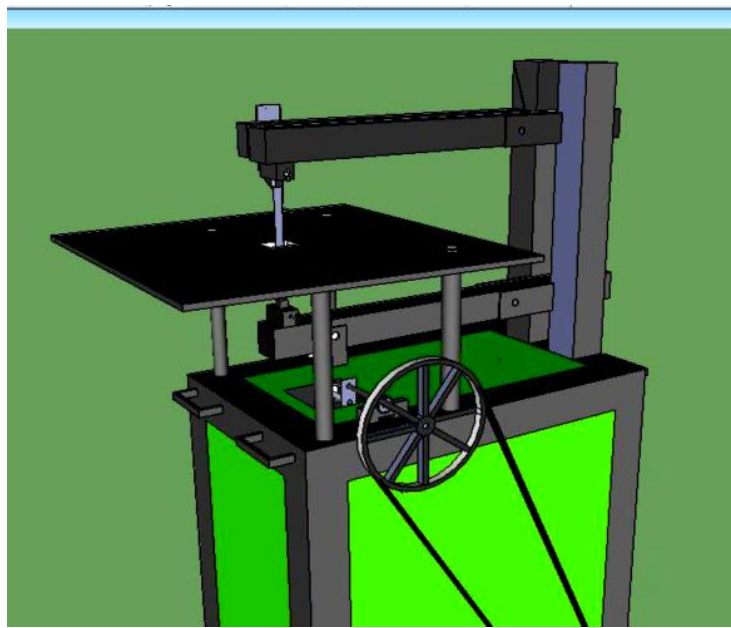

Gambar 3 desain dari samping kanan

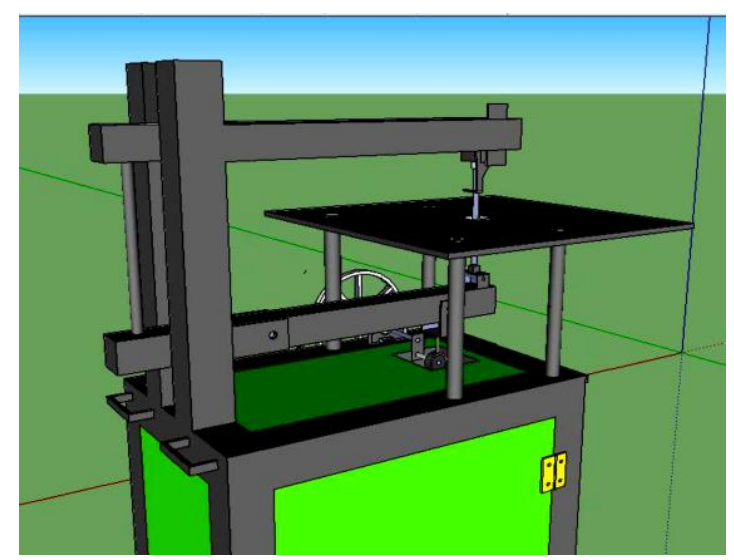

Gambar 4. Gambar desain samping kiri

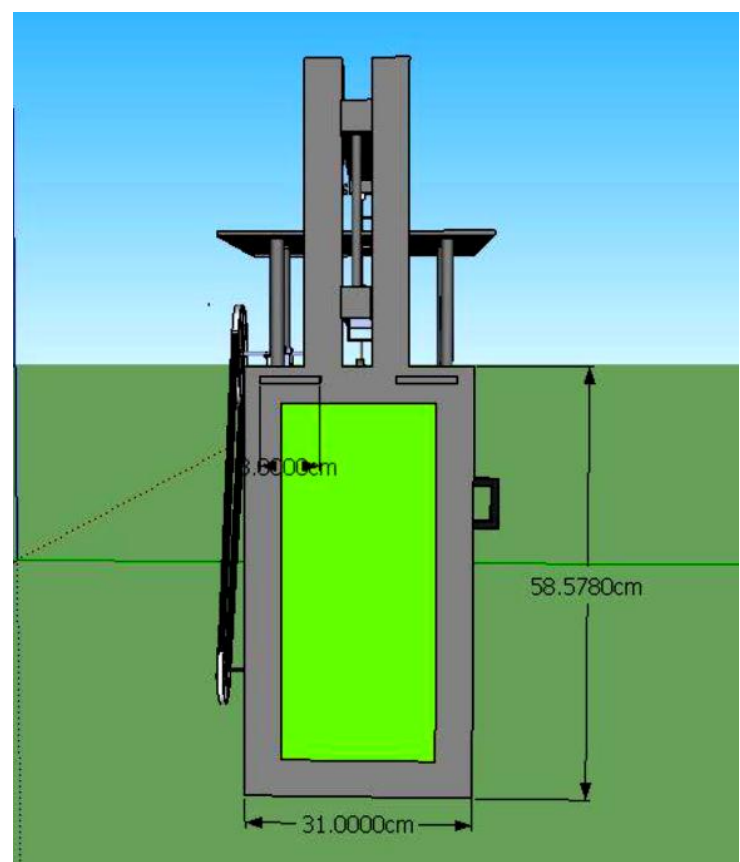

Gambar 5. Gambar desain tampak dari belakang

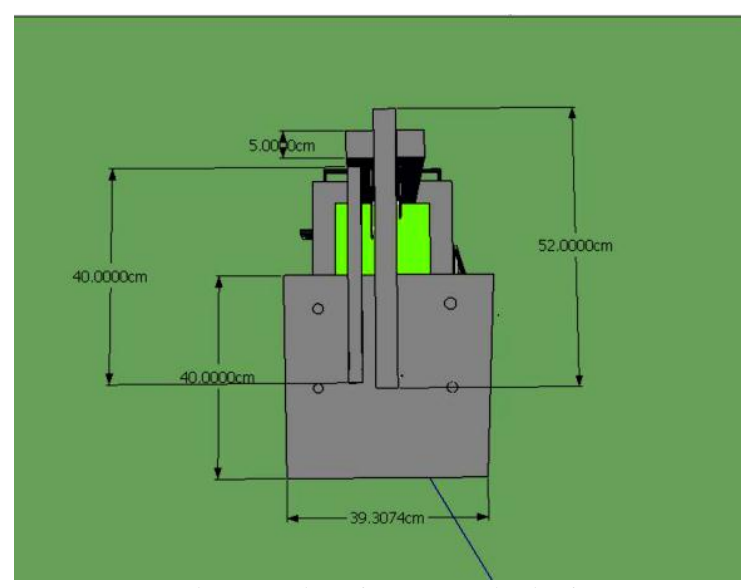

Gambar 6. desain tampak dari atas

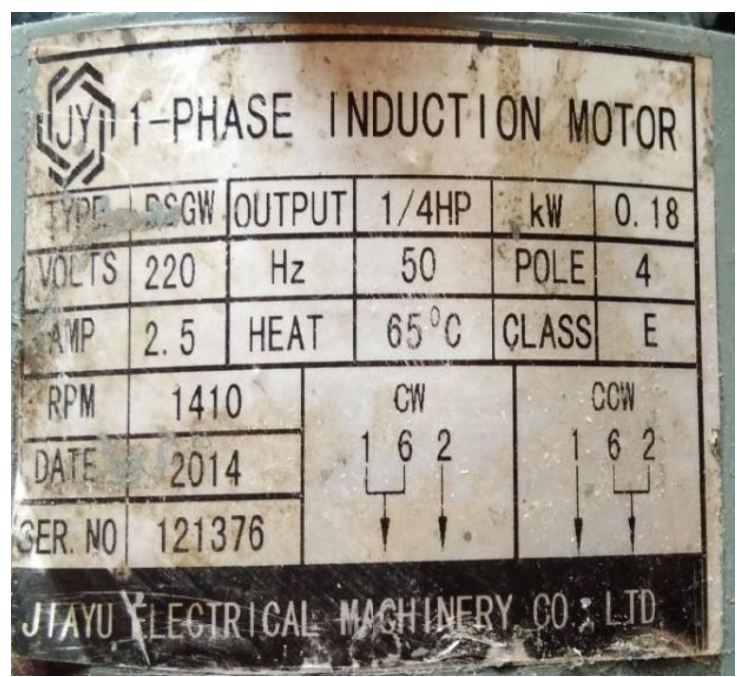

Gambar 7. Nameplate Motor Penggerak 
Unit penggerak dan sistem transmisi pada sistem transmisi daya dan sistem penggerak ini komponen utamanya adalah berupa motor AC 1 fasa kapasitor start dan puli beserta sabuk V. Selanjutnya untuk sistem transmisi dayanya menggunakan puli dan sabuk $\mathrm{V}$, dengan perbandingan seperti di bawah ini:

Keliling pulley $1=2 . \pi \cdot \mathrm{r}$

$$
\begin{aligned}
& =2 \times 3,14 \times 3,75 \\
& =23.55 \mathrm{~cm} \\
& =0.235 \mathrm{~m}
\end{aligned}
$$

Keliling pulley $=2 . \pi \cdot r$

$$
\begin{aligned}
& =2 \times 3.14 \times 12.5 \\
& =78.5 \mathrm{~cm} \\
& =0.785 \mathrm{~m}
\end{aligned}
$$

Berdasarkan hukum fisika mengenai gerak melingkar pada roda-roda yang dihubungkan dengan menggunakan sabuk berlaku dua hal. Pertama, arah putaran kedua roda akan sama. Kedua, gerak laju putaran kedua roda akan sama. Perbandingan antara kecepatan pulley penggerak atau sumber pulley ini dengan pulley pengikut ditulis dengan persamaan sebagai berikut (Tim Kemendikbud, 2015:117):

dimana:

$$
\begin{aligned}
\frac{N 2}{N 1} & =\frac{D 1}{D 2} \\
\frac{N 2}{1410} & =\frac{75}{250} \\
250 . \mathrm{N} 2 & =105750 \\
\mathrm{~N} 2 & =423 \mathrm{RPM}
\end{aligned}
$$

$\mathrm{D} 1=$ Diameter pulley penggerak $(\mathrm{mm})$

$\mathrm{D} 2=$ Diameter pulley pengikut $(\mathrm{mm})$

$\mathrm{N} 1=$ Kecepatan pulley penggerak (RPM)

N2= Kecepatan pulley pengikut (RPM)

\section{Unit Pengendali Kecepatan Berbasis PWM dan komponen kelistrikan}

1. Modul Arduino

Modul arduino ini berfungsi untuk membuat program- program yang akan digunakan untuk pengendali kecepatan motor AC 1 fasa. Output dari arduino ini akan masuk ke modul Zero Crossing Detector berupa sinyal digital.

\section{Modul Zero Crossing Detector}

Modul ini berfungsi sebagai penerima dari outputan arduino yang berupa sinyal digital untuk pemicuan TRIAC yang ada pada modul ini dan modul Zero Crossing Detector juga merupakan driver motor AC 1 fasa.

\section{LCD (Liquid Crystal Display)}

LCD ini digunakan untuk menampilkan presentase kecepatan yang diatur pada modul pengendali.

4. Potensio

Potensio ini digunakan untuk mengatur kecerahan dari LCD tersebut sesuai dengan tingkat kecerahan yang diinginkan. 50

5. Kabel

Kabel ini digunakan untuk menghubungkan antar komponen yang ada dalam modul pengendali ini, sekaligus untuk penghubung agar arus bisa mengalir ke setiap komponen.

6. PTB (Push to Brake) switch/ NCPB (Normaly-Close-Push-Button)

Komponen ini digunakan untuk memberikan input ke arduino berupa sinyal high (pull up) atau low (pull down). Komponen ini dihubungkan dengan pin A0 (pull up) dan A1 (pull down) pada arduino.

\section{Casing}

Casing yang digunakan untuk pengendali kecepatan berbasis PWM ini langsung dibeli dalam bentuk jadi, berbentuk balok. Sehingga pada bagian ini hanya membuat lubang yang digunakan untuk soket catu daya dan soket untuk USB, serta untuk lubang berbentuk persegi panjang sesuai dengan ukuran LCD yang digunakan.

8. Kabel USB untuk Arduino

Digunakan untuk menghubungkan arduino dengan PC dan juga untuk mengupload program-program yang ditulis pada PC ke arduino. 


\section{9. $\mathrm{MCB}$ (Miniature Circuit Breaker)}

MCB (Miniature Circuit Breaker) merupakan alat pengaman arus lebih dan pengaman apabila terjadi short circuit untuk tegangan rendah

10. Konverter

Konverter AC to DC merupakan sebuah rangkaian elektronika daya yang berfungsi sebagai pengubah tegangan sumber masukan arus bolak-balik dalam bentuk sinusoida menjadi tegangan luaran dalam bentuk tegangan searah yang tetap (Muhammad Ali, 2010:13).

11. Steker dan stop kontak

Steker adalah komponen listrik yang dipasang pada ujung kabel berbentuk colokan yang digunakan untuk menghubungkan aliran listrik dengan peralatan listrik dengan memasukan colokan tersebut ke dalam lubang stop kontak. Kotak kontak ialah sebuah kotak yang dipergunakan untuk menempatkan kabel, sehingga kotak kontak tersebut merupakan tempat sumber tegangan (Basrowi, 1995:36)

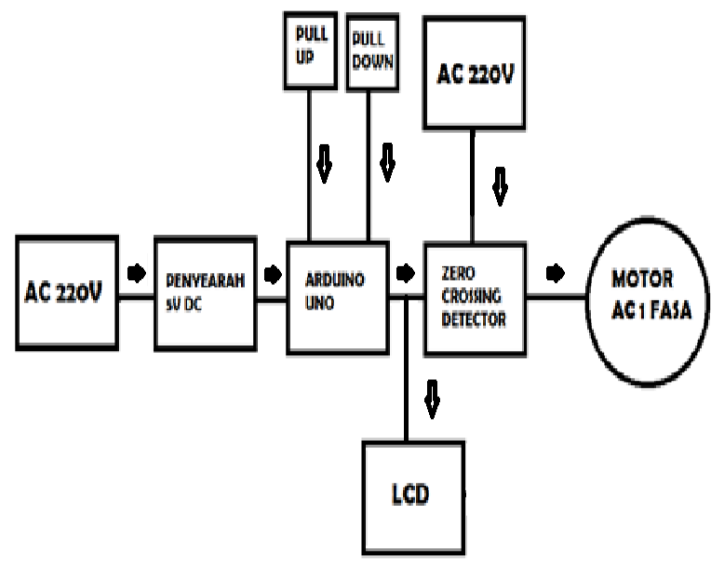

Gambar 8. Blok Diagram pengendali

Poses pengendalian dilakukan dengan tahapan berikut ini ; Sumber tegangan AC $220 \mathrm{~V}$ masuk ke penyerarah agar keluarannya keluar menjadi $5 \mathrm{~V}$ DC untuk bisa digunakan sebagai sumber pada arduino. Kemudian untuk dapat mengatur kecepatan motor maka dipasangi 2 buah push button yaitu pull up (A0) dan pull down (A1) . Inputan yang berasal dari push button berupa sinyal high atau low. Selanjutnya dari arduino masuk ke Zero Crossing Detector berupa sinyal digital yang digunakan untuk pemicuan TRIAC. LCD akan menampilkan presentase kecepatan motor. Motor akan menyala sesuai dengan pengaturan kecepatan yang diatur.

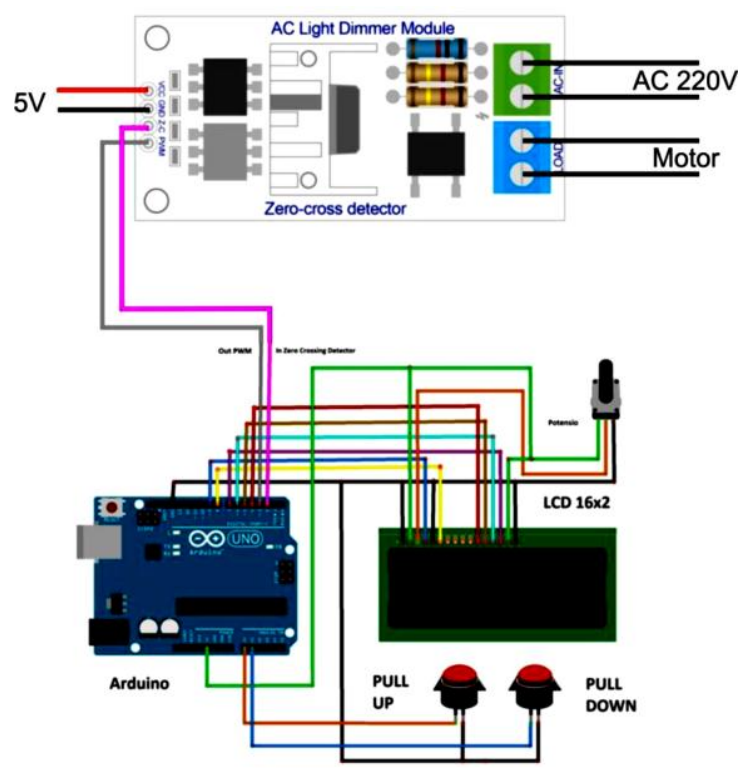

Gambar 9. Rangkaian Pengendali Kecepatan dengan Pengaturan Berbasis PWM

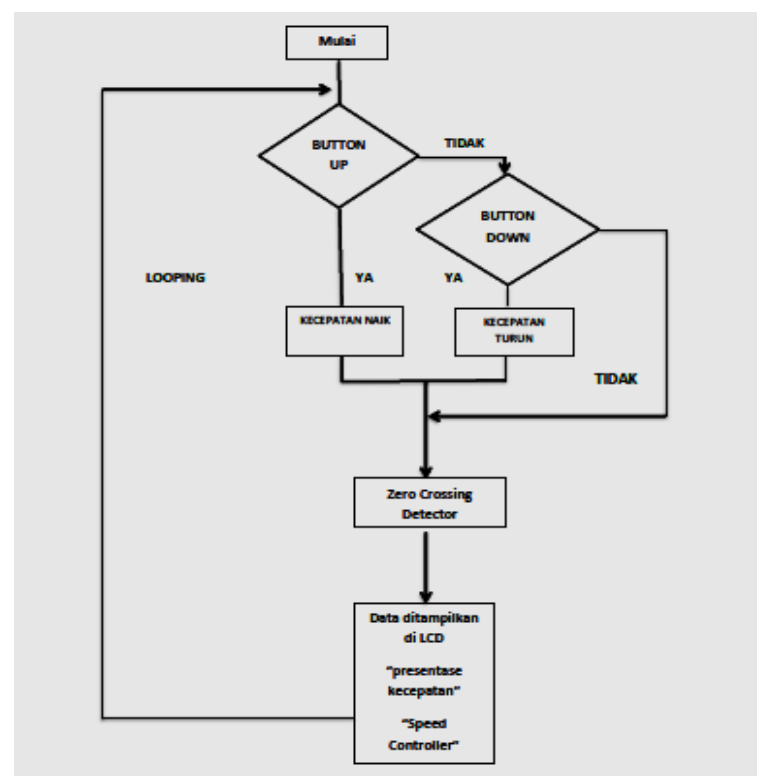

Gambar 10. Flowchat Pemrograman 


\section{Cara Kerja Mesin}

Kemudian untuk pengaturan PWMnya adalah sebagai berikut; Ketika diberi masukkan dengan menggunakan push button maka arduino akan menerima sinyal tersebut, berupa sinyal HIGH atau LOW. Kemudian LCD akan menampilkan presentase tersebut, misal presentase $50 \%$. Pengaturan PWM adalah mengatur waktu t-on dan t-off dengan satuan milidetik, apabila mengatur dengan kecepatan $50 \%$ maka waktu yang dibutuhkan ketika t-on dan t-off adalah 100 (dimtime) x 50=5000 mikrodetik (5 milidetik). Berikut ini gambar gelombang PWM sinusioda yang telah dimanipulasi:

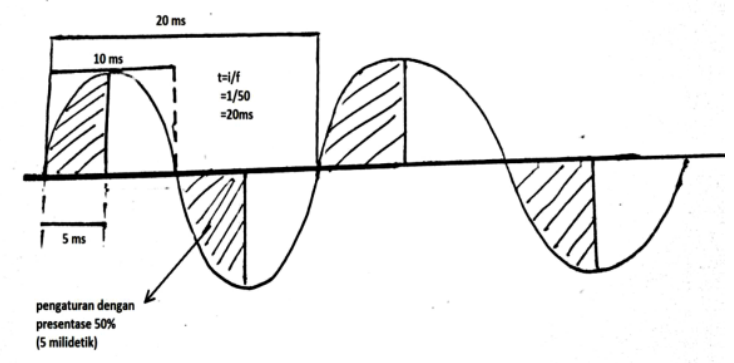

Gambar 11. Gelombang PWM sinusioda yang telah dimanipulasi

Kemudian output dari arduino akan masuk ke modul zero crossing detector berupa sinyal digital yang digunakan untuk pemicuan TRIAC.

\section{HASIL DAN PEMBAHASAN}

Pengujian alat pemotong kayu dengan pengaturan kecepatan berbasis PWM merupakan sebuah tahapan yang dilakukan guna mengetahui unjuk kerja dari alat tersebut. Pengujian ini dilakukan untuk dapat mengukur tegangan, arus, frekuensi dan RPM pada saat berbeban dan tidak berbeban serta waktu yang dibutuhkan untuk proses pemotongan kayu. Pengujian alat pemotong kayu dengan pengatur kecepatan berbasis PWM ini meliputi uji komponen dari alat pemotong kayu dengan pengatur kecepatan berbasis PWM dan unjuk kerja dari alat tersebut. Berikut disajikan hasil dari pengujian pemotong kayu dengan pengaturan kecepatan berbasis PWM:

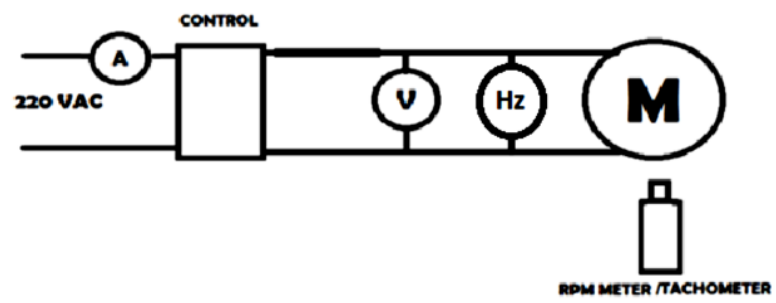

Gambar 12. Gambar Rangkaian Pengujian Berbeban

Tabel 1. Pengujian dengan kayu ketebalan 0.5 $\mathrm{cm}$

\begin{tabular}{|c|c|}
\hline Variabel & Ketebalan $0.5 \mathrm{~cm}$ \\
\hline Persentase kecepatan & $30 \%$ \\
\hline Tegangan & $155 \mathrm{~V}$ \\
\hline Arus & $1.65 \mathrm{~A}$ \\
\hline $\begin{array}{l}\text { Kecepatan pada puli } \\
\text { Penggerak }\end{array}$ & 636.5 RPM \\
\hline $\begin{array}{l}\text { Kecepatan pada puli } \\
\text { Pengikut }\end{array}$ & $198 \mathrm{RPM}$ \\
\hline Frekuensi & $50 \mathrm{~Hz}$ \\
\hline Waktu & $88 \mathrm{~s} / 1.28$ menit \\
\hline Nama Kayu & $\begin{array}{l}\text { Jati umur sekitar } 10 \\
\text { tahun }\end{array}$ \\
\hline Bentuk & $\begin{array}{l}\text { Lingkaran dengan } \\
\text { diameter } 12 \mathrm{~cm}\end{array}$ \\
\hline
\end{tabular}

Tabel 2. Pengujian dengan kayu ketebalan $1 \mathrm{~cm}$

\begin{tabular}{|l|l|}
\hline \multicolumn{1}{|c|}{ Variabel } & \multicolumn{1}{|c|}{ Ketebalan $\mathbf{1 ~ c m}$} \\
\hline Persentase kecepatan & $50 \%$ \\
\hline Tegangan & $160 \mathrm{~V}$ \\
\hline
\end{tabular}




\begin{tabular}{|l|l|}
\hline \multicolumn{1}{|c|}{ Variabel } & \multicolumn{1}{c|}{ Ketebalan 1 cm } \\
\hline Arus & $1.7 \mathrm{~A}$ \\
\hline $\begin{array}{l}\text { Kecepatan pada puli } \\
\text { Peenggerak }\end{array}$ & $1124.8 \mathrm{RPM}$ \\
\hline $\begin{array}{l}\text { Kecepatan pada puli } \\
\text { Pengikut }\end{array}$ & $345.44 \mathrm{RPM}$ \\
\hline Frekuensi & $50 \mathrm{~Hz}$ \\
\hline Waktu & $135 \mathrm{~s}$ \\
\hline Nama Kayu & Jati umur 20 tahunan \\
\hline Bentuk & $\begin{array}{l}\text { Lingkaran dengan } \\
\text { diameter } 12 \mathrm{~cm}\end{array}$ \\
\hline
\end{tabular}

Tabel 3. Pengujian dengan kayu ketebalan $2 \mathrm{~cm}$

\begin{tabular}{|l|l|}
\hline \multicolumn{1}{|c|}{ Variabel } & Ketebalan 2 cm \\
\hline Persentase Kecepatan & $65 \%$ \\
\hline Tegangan & $170 \mathrm{~V}$ \\
\hline Arus & $1.8 \mathrm{~A}$ \\
\hline $\begin{array}{l}\text { Kecepatan pada puli } \\
\text { Peenggerak }\end{array}$ & $1273 \mathrm{RPM}$ \\
\hline $\begin{array}{l}\text { Kecepatan pada puli } \\
\text { Pengikut }\end{array}$ & $387.9 \mathrm{RPM}$ \\
\hline Frekeunsi & $50 \mathrm{~Hz}$ \\
\hline Waktu & $180 \mathrm{~s} / 3$ menit \\
\hline Nama Kayu & $\begin{array}{l}\text { Kayu Nangka } \\
\text { umur 20 tahunan }\end{array}$ \\
\hline Bentuk & $\begin{array}{l}\text { Lingkaran dengan } \\
\text { diameter 12 cm }\end{array}$ \\
\hline
\end{tabular}

Tabel 4. Pengujian dengan kayu ketebalan $3 \mathrm{~cm}$

\begin{tabular}{|c|c|}
\hline Variabel & Ketebalan $3 \mathrm{~cm}$ \\
\hline Persentase Kecepatan & $85 \%$ \\
\hline Tegangan & $185 \mathrm{~V}$ \\
\hline Arus & $1.8 \mathrm{~A}$ \\
\hline $\begin{array}{l}\text { Kecepatan pada puli } \\
\text { Peenggerak }\end{array}$ & 1349 RPM \\
\hline $\begin{array}{l}\text { Kecepatan pada puli } \\
\text { Pengikut }\end{array}$ & $410.75 \mathrm{RPM}$ \\
\hline Frekuensi & $50 \mathrm{~Hz}$ \\
\hline Waktu & $1560 \mathrm{~s} / 26$ menit \\
\hline Nama Kayu & $\begin{array}{l}\text { Jati umur sekitar } \\
30 \text { tahunan }\end{array}$ \\
\hline Bentuk & $\begin{array}{l}\text { Lingkaran dengan } \\
\text { diameter } 12 \mathrm{~cm}\end{array}$ \\
\hline
\end{tabular}

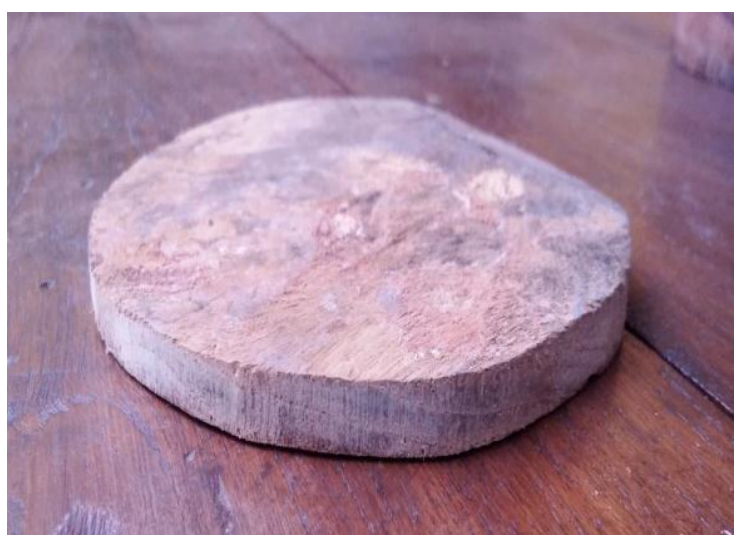

Gambar 13. Hasil pemotongan kayu dengan ketebalan $0.5 \mathrm{~cm}$ 


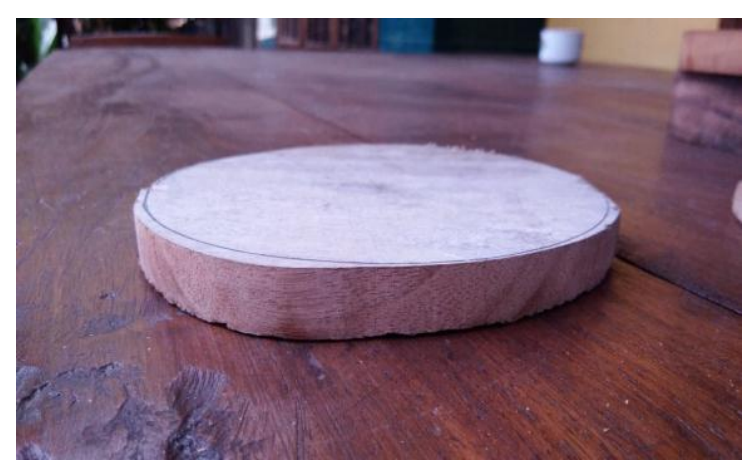

Gambar 14. Hasil pemotongan kayu dengan ketebalan $1 \mathrm{~cm}$

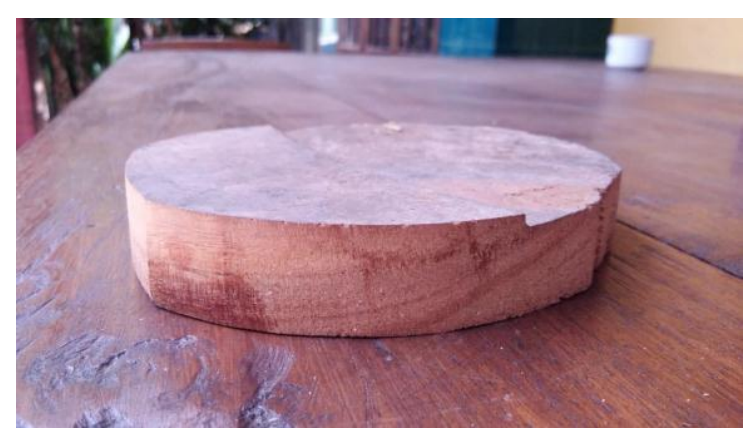

Gambar 15. Hasil pemotongan kayu dengan ketebalan $2 \mathrm{~cm}$

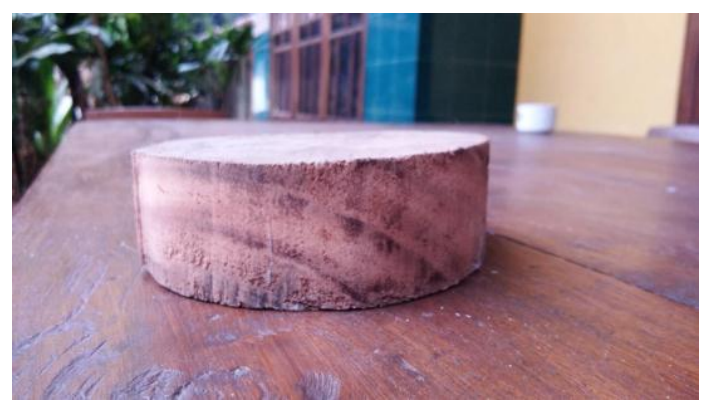

Gambar 16. Hasil pemotongan kayu dengan ketebalan $3 \mathrm{~cm}$

Berdasarkan dari data tersebut maka dapat dihitung berapa daya yang digunakan, kemudian memperkirakan biaya setiap hari, bulan dan tahunnya. Sebagai sampel diambil contoh pada data pemotongan kayu dengan ketebalan $0.5 \mathrm{~cm}$.

\section{Kayu dengan ketebalan $0.5 \mathrm{~cm}$}

Hasil potongan selama 1 jam:

$=1 \mathrm{jam}$ (menit) $:$ waktu yang dibutuhkan untuk 1 buah potongan

$=60$ menit: 1,28 menit

$=46 \mathrm{buah} / \mathrm{jam}$

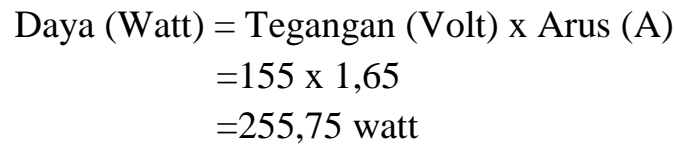

\section{Penggunaan dalam sehari:}

$=255,75$ watt $\times 7$ jam

$=1790,25 \mathrm{Wh}$

$=1,79 \mathrm{kWh}$

Biaya $=$ tarif dasar listrik per $\mathrm{kWh} \mathrm{x}$

penggunaan daya

$=$ Rp. $1407,28 \times 1,79 \mathrm{kWh}$

$=$ Rp. $2.519,38$

Penggunaan dalam sebulan:

$=1.79 \mathrm{kWh} \times 26$ hari (sebulan dan minggu libur)

$=46,54 \mathrm{kWh}$

Biaya $=$ tarif dasar listrik per $\mathrm{kWh} \mathrm{x}$ penggunaan daya

$=$ Rp. $1407,28 \times 46,54 \mathrm{kWh}$

$=$ Rp. $65.494,81$

\section{Penggunaan dalam setahun:}

$=46,54 \mathrm{kWh} \times 12$ bulan 85

$=558,48 \mathrm{kWh}$

Biaya $=$ tarif dasar listrik per $\mathrm{kWh} \mathrm{x}$ penggunaan daya $=$ Rp. $1407,28 \times 558,48 \mathrm{kWh}$ $=$ Rp. $785.937,73$

Jadi jika kayu dengan ukuran $0,5 \mathrm{~cm}$ maka alat pemotong kayu dengan pengaturan kecepatan berbasis PWM ini dapat menghasilkan:

1. 329 buah/ Rp. 2.519,38 (dalam satu hari)

2. 8.554 buah/ Rp. $65.494,81$ (dalam satu bulan)

3. 102.648 buah/ Rp.785.937,73 (dalam satu tahun)

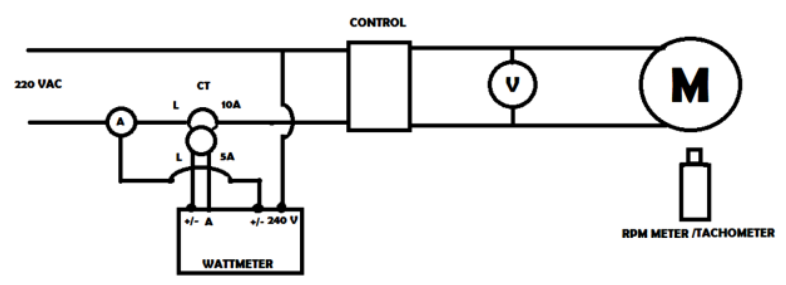

Gambar 17. Gambar Rangkaian ketika Berbeban 
Tabel 5. Data ketika Beban Kosong

\begin{tabular}{|c|l|l|l|l|l|l|l|}
\hline No. & $\begin{array}{l}\text { Persen } \\
\text { Pengatur } \\
\text { Kecepatan } \\
(\text { V) }\end{array}$ & & $\begin{array}{l}\text { Arus } \\
(\mathbf{A})\end{array}$ & $\begin{array}{l}\text { Daya } \\
\text { Watt) }\end{array}$ & $\begin{array}{l}\text { Kecepatan } \\
\text { Putaran } \\
\text { Motor pada } \\
\text { Puli } \\
\text { Penggerak } \\
\text { (RPM) }\end{array}$ & $\begin{array}{l}\text { Kecepatan } \\
\text { Putaran } \\
\text { Motor } \\
\text { pada } \\
\text { Puli } \\
\text { Pengikut } \\
\text { (RPM) }\end{array}$ & $\begin{array}{l}\text { Frekuensi } \\
(\text { Hz) }\end{array}$ \\
\hline 1. & $0 \%$ & 20 & 0.9 & 19.5 & 0 & 0 & 82 \\
\hline 2. & $5 \%$ & 30 & 1 & 28 & 0 & 0 & 95 \\
\hline 3. & $10 \%$ & 35 & 1 & 38.5 & 0 & 0 & 98 \\
\hline 4. & $15 \%$ & 43 & 1.7 & 73 & 0 & 0 & 97 \\
\hline 5. & $20 \%$ & 50 & 2.3 & 119 & 0 & 0 & 94 \\
\hline 6. & $25 \%$ & 60 & 2.7 & 157 & Starting $(0)$ & 0 & 50 \\
\hline & & 135 & 1.7 & 230 & $\begin{array}{l}\text { Running } \\
(680.5)\end{array}$ & 207.15 & 50 \\
\hline 7. & $30 \%$ & 141 & 1.8 & 250 & 721.5 & 219.45 & 50 \\
\hline 8. & $35 \%$ & 145 & 1.8 & 262 & 751.5 & 224 & 50 \\
\hline 9. & $40 \%$ & 151 & 1.8 & 272 & 796 & 241.35 & 50 \\
\hline 10. & $45 \%$ & 155 & 1.8 & 280 & 865 & 260 & 50 \\
\hline 11. & $50 \%$ & 160 & 1.85 & 295.5 & 895 & 269.55 & 50 \\
\hline 12. & $55 \%$ & 165 & 1.90 & 315 & 924.5 & 276.79 & 50 \\
\hline 13. & $60 \%$ & 172 & 1.90 & 325 & 958 & 289.7 & 50 \\
\hline 14. & $65 \%$ & 175 & 1.95 & 340.5 & 980.5 & 296 & 50 \\
\hline 15. & $70 \%$ & 180 & 1.95 & 350 & 1015.5 & 305.65 & 50 \\
\hline 16. & $75 \%$ & 185 & 1.95 & 359 & 1075 & 320.55 & 50 \\
\hline 17. & $80 \%$ & 190 & 2 & 378.5 & 1119.5 & 334.85 & 50 \\
\hline 18. & $85 \%$ & 195 & 2 & 380 & 1150 & 345 & 50 \\
\hline 19. & $90 \%$ & 201 & 2 & 398 & 1178 & 355.45 & 50 \\
\hline 20. & $95 \%$ & 205 & 2 & 408.5 & 1216 & 368.88 & 50 \\
\hline 21. & $100 \%$ & 212.5 & 2.2 & 410 & 1284 & 390 & 50 \\
\hline & & & & & & & \\
\hline
\end{tabular}

\section{SIMPULAN}

\section{Kesimpulan}

Berdasarkan hasil yang diperoleh dari uji coba alat yang telah dibuat, maka dapat ditarik kesimpulan sebagai berikut:

1. Konstruksi dari pemotong kayu dengan pengendali berbasis PWM ini terdiri dari body penopang, penggerak, mata gergaji, modul pengendali berbasis PWM, pulley beserta dengan $V$-Belt sebagai media transmisinya, dan motor AC 1 fasa $1 / 4 \mathrm{HP}$ kapasitor start sebagai penggeraknya.

2. Unjuk kerja pemotong kayu dengan pengatur kecepatan berbasis PWM. Alat ini mampu memotong kayu dengan bentuk lingkaran berdiameter $12 \mathrm{~cm}$ dari mulai ketebalan: a. Ketebalan 0,5 cm memerlukan waktu pemotongan 88 detik

b. Ketebalan $1 \mathrm{~cm}$ memerlukan waktu pemotongan 135 detik

c. Ketebalan $2 \mathrm{~cm}$ memerlukan waktu pemotongan 180 detik

d. Ketebalan $3 \mathrm{~cm}$ memerlukan waktu pemotongan 1560 detik

3. Kemudian konsumsi daya mulai dari 255,75 sampai 333 watt tergantung dengan ketebalan kayu yang digergaji. Semakin tebal kayu yang digergaji maka daya yang dikonsumsi juga akan semakin besar.

\section{Saran}

Saran yang dapat membangun dan menyempurnakan alat pemotong kayu dengan 
pengaturan kecepatan berbasis PWM adalah sebagai berikut:

1. Menambahkan laker pada lengan penggerak pada bagian atas dan bawah.

2. Menggunakan bahan rangka yang lebih ringan, tentunya tidak mengurangi kualitas produk.

3. Merubah penjepit agar posisi pemotongan kayu bisa dilakukan dari arah kiri menuju kanan.

\section{DAFTAR RUJUKAN}

Ali, Muhammad. 2011. Modul Kuliah Elektronika Daya "Pengantar Elektronika Daya”. Yogyakarta: Tidak diterbitkan.

Arduino Uno. 2011. Arduino Uno. Italia: Arduino Uno.

Arindya, Radita. 2013. Pengunaan dan Pengaturan Motor Listrik. Yogyakarta: Graha Ilmu.

Ashari, Mochamad. 2017. Desain Konverter Elektronika Daya. Bandung: Informatika Bandung.

Basrowi. 1995. Instalasi Penerangan. Yogyakarta: Jurusan Pendidikan Teknik Elektro FPTK IKIP Yogyakarta.

Bayuseno, Athanasius P. 2016. Analisa Laju Korosi pada Baja untuk Material Kapal Dengan dan Tanpa Perlindungan Cat. Jurnal Teknik Mesin Volume 11 Nomor 3, hal. 32-37

Bolymin, Inc. 2005. LCD MODULE SPECIFICATION MODEL NO. BC1602A series. Taichung City 403, Taiwan: Bolymin, Inc.

Firdausi, Arif. 2013. Mekanika dan Elemen Mesin. Jakarta: Kementerian dan Kebudayaan RI.

Fatori, Muhammad. 2013. Peralatan dan Mesin Pengerjaan Kayu. Cimahi: Kementrian Pendidikan Dan Kebudayaan (Direktorat Pembinaan Sekolah Menengah Kejuruan).
Haryanto, T. 2016. Analog Output pada Arduino Menggunakan PWM (Pulses Width Modulation). Diakses dari https://www.codepolitan.com/analogoutput-arduino-menggunakan-pwmpulse-width-modulation. Pada 19 Juli 2018 pukul 11:30 WIB.

Muis, Saludin. 2013. Prinsip Kerja LCD dan Pembuatannya (Liquid Crystal Display). Yogyakarta: Graha Ilmu.

Pudjiono, Sugeng. 2014. Produksi Bibit Jati Unggul (Tectona Grandis L.F) dari Klon dan Budidayanya. Jakarta: IPB PRESS.

Rusdi, Akhbar Prachaessardhi. 2014. Sistem Pengendalian Suhu pada Proses Distilasi Vakum Bioetanol Menggunakan Kontrol Logika Fuzzy. Jurnal Teknik Elektro punlikasi Februari 2014, hal 1-6.

Satriawan, Mirza. 2004. Instalasi Listrik Dasar. Jakarta: Erlangga.

Santoso, Hari. 2015. Panduan Praktis Arduino Untuk Pemula (ebook). Trenggalek: https://fajarahmadfauzi.files.wordpress.c om/2016/04/ebook-gratis-arduino-untukpemula-v1.pdf.

Sunaryo, Heri. 2008. Teknik Pengelasan Kapal Jilid 2. Jakarta: Direktorat Pembinaan Sekolah Menengah Kejuruan.

Suhali. 2007. Faktor-Faktor Strategik dalam Peningkatan Belajar Ukir Kayu (Studi Kasus: Pada Sanggar Ukir di Jepara). Tesis Magister, tidak diterbitkan, Universitas Muhammadiyah Surakarta, Surakarta

Sumanto. 1993. Motor Listrik Arus BolakBalik. Yogyakarta: Andi Offset

Tim Kemendikbud. 2015. Mekanika Teknik dan Elemen Mesin 2. Jakarta:Kementerian Pendidikan dan Kebudayaan Republik Indonesia.

Tri T, Tedy. 1998. Mengelola Bengkel Las. Jakarta:Puspa Swara. 